Archived version from NCDOCKS Institutional Repository http://libres.uncg.edu/ir/asu/

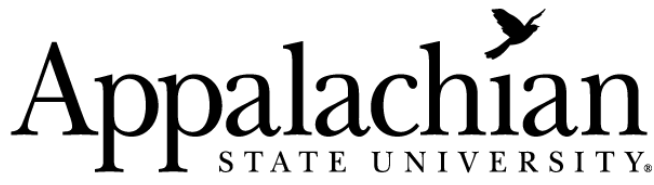

B O O NE, NORTH CAROLINA

\section{Mental Accounting and Other-Regarding Behavior: Evidence from the Lab}

\author{
By: Todd L. Cherry
}

\begin{abstract}
This paper uncovers a key determinant of the other-regarding behavior that permeates bargaining experiments. Examining a one-shot dictator game that has the first-mover dictate the split of an amount of money, dictators acting over earned money exhibited self-interested behavior in $76 \%$ of bargains. This result stands in stark contrast to the baseline experiment in which dictators acting over allocated money displayed self-interested behavior in only $26 \%$ of bargains. Self-interested behavior appeared at greater levels using an earnings protocol than any previous variation of the dictator game. While the distinction between earned and unearned wealth is likely context specific, the earnings protocol may be an important option for future laboratory research. Specifically, the earnings protocol may provide a closer correspondence between the laboratory and individual choices over personal assets.
\end{abstract}

Todd L. Cherry (2001) "Mental Accounting and Other-Regarding Behavior: Evidence from the Lab" Journal of Economic Psychology Volume 22 Issue 5 pp.605-615 [DOI: 10.1016/S0167-4870(01)00058-7] Version of Record Available From (www.sciencedirect.com) 


\section{Introduction}

Experimental evidence indicates that individuals often exhibit other-regarding behavior when bargaining with other people. This result appears to contradict the presumption of self-interest in classic economic theory and has prompted an intense debate within behavioral economics. While some contend that theory should be extended to capture the anomalistic behavior (Thaler, 1988), others suggest that other-regarding behavior actually arises from veiled or faint concerns of self-interest (Baik, Cherry, Kroll, \& Shogren, 1999; Forsythe, Horowitz, Savin, \& Sefton, 1994; Hoffman, McCabe, \& Smith, 1996a). Efforts to uncover self-interested behavior have found some success in complex bargaining games (e.g., Shogren, 1997), but equivalent heroic efforts have failed in simple bargaining games.

This study uses the concept of mental accounting to explore other-regarding behavior in a new context. Mental accounting proposes that people act differently over money from different sources with people possessing different marginal propensities to consume for each type of wealth (Thaler, 1985, 1990). Evidence suggests that people do partake in such bookkeeping. Keeler, James, and Abdel-Ghany (1985) find that people handle unexpected money differently than their regular earned income. More specifically, the results suggest that unexpected windfalls have a higher propensity to consume when the windfall is small relative to their regular income. This, of course, is the case in many experimental settings. Subsequent work reveals that people spend relatively more and accept more risk when acting over unearned money (Arkes et al., 1995; Battalio, Kagel, \& Jiranyakul, 1990; Thaler \& Johnson, 1990; Keasey \& Moon, 1996).

The transition of mental accounting to bargaining requires the assumption that people are consumers at the bargaining table. Many argue that otherregarding behavior in simple bargaining games arises from concerns of reciprocity (Hoffman, McCabe, Shachat, \& Smith, 1994). Bargainers exhibiting other-regarding behavior are therefore consuming prospective reciprocity. From this perspective, mental accounting at the bargaining table may be evident when the rate of other-regarding behavior (i.e., the propensity to consume prospective reciprocity) varies over different money sources.

\footnotetext{
${ }^{1}$ For example, Hoffman et al. (1996a) meticulously develops an anonymous dictator game to control for reciprocity concerns. But even with the numerous safeguards within the experimental design, other-regarding behavior persisted in approximately $40 \%$ of the bargains. Note the terms complex and simple refer to the relative complexity of the bargaining framework. The ultimatum and dictator games are typically characterized as simple games while Coasean bargains are more complex and demanded of time and effort.
} 
Alternatively, many contend that selfless behavior is altruistic. This implies that different sources of incomes simply alter the perceived deservingness for respective bargainers. Ruffle (1998) uses this rationale to explain his finding that other-regarding behavior decreases in the dictator game when the recipient determines the amount of money on the table. Similarly, Hoffman et al. (1994) suggests that the origin of bargaining power will alter the deservingness of bargainers. They find that legitimizing the relative bargaining position with competition increases self-interest. Other studies have argued deservingness varies across bargainers' characteristics such as if the party is a charitable organization (Eckel \& Grossman, 1996). Whether other-regarding behavior is self-interested consumption or altruistic, the same question arises: does other-regarding behavior vary when bargainers act over unearned and earned money?

Herein we examine the impact of unearned money on other-regarding behavior in a simple bargaining game. Contrary to previous studies, our experimental design has people bargain over earned assets rather than unearned assets granted by the experimenter. Following the literature, the legitimacy of assets gained from effort is hypothesized to decrease otherregarding behavior. Results not only support this hypothesis, but the role of unearned assets accounts for more other-regarding behavior than any previous conjecture. The distinction between earned and unearned assets appears important and raises questions and opportunities for future theoretical and experimental work.

\section{Experimental design}

Two hundred undergraduate students from the University of Wyoming and Appalachian State University were recruited to participate in two experimental treatments: baseline and earnings. In each treatment, 100 subjects were randomly assigned to one of two rooms with half being in Room A and the other half in Room B. The two groups did not have any contact before, during or after the treatment session, but were assured of the existence of the other group. Within each room, subjects could not communicate with anyone other than an administrator. The experimental design established a written protocol to ensure consistency and involved two stages: earnings and bargaining.

The earnings treatment initially directed subjects in Room A to participate in an earnings session. The session entailed multiple decision-making tasks that yielded monetary earnings (see Cherry, Crocker, \& Shogren, 2001). 
Specifically, subjects were endowed with money for participation in a market for money lotteries (e.g., 75\% chance of winning $\$ 10$ and $25 \%$ chance of losing \$1). Each subject could submit requests to buy, sell and trade available lotteries according to their individual valuations and preferences. Subsequent market agreements and transactions adjusted the subject's money balance and portfolio of lotteries. When the market closed, lotteries were played with winnings (losses) being added to (subtracted from) the subject's money balance. Fifteen such market sessions lasted approximately 1 hour and accumulated earnings from each session provided total payoffs between 16 and 28 US\$ per subject. ${ }^{2}$ The level of earnings for a subject was solely determined by the decisions of that subject and chance. After being paid, subjects were informed that they would participate in a bargaining session. ${ }^{3}$

The bargaining framework was a one-shot dictator game. The dictator game is a one-stage bargain between two parties where the first-mover dictates the outcome. Due to the absence of strategic concerns from a secondstage, the dictator game is the appropriate framework to examine otherregarding behavior (Hoffman et al., 1996a). As in previous studies, we followed Forsythe et al. (1994) for our experimental design. The experimental instructions were identical to Forsythe et al. (1994) except for the minor adjustments necessary to incorporate whether the money was allocated by the experimenter or earned by the dictator.

The bargaining session began with each person in Room A being randomly paired with a person in Room B. The person in Room A was the dictator and decided how to split his or her earnings or allocation with the person in Room B. In the earnings treatment, earnings varied according to the outcomes of the earnings session. ${ }^{4}$ In the baseline treatment, allocations were set to mimic the amounts established in the earnings treatment for control purposes. ${ }^{5}$

Whether the money is earned or unearned, the game-theoretic solution is the person in Room A not offering any positive amount to the person in

\footnotetext{
${ }^{2}$ The instructions from the earnings session are available from the author.

${ }^{3}$ Waiting to announce the second bargaining stage until after the completion of the earnings stage was to ensure subjects were under the impression they were earning money for themselves rather than a team.

${ }^{4}$ For logistic reasons, the earnings treatment had subjects assigned to Room B arrive 1 hour later than those assigned to earn money in Room A. In both treatments, subjects in Room B were informed that the money on the bargaining table was either allocated by the experimenter or earned by the dictator in a previous session while the dictators were informed the subjects in room B did not have such an opportunity.

${ }^{5}$ As such the baseline treatment was conducted after the earnings treatment. The various allocation levels were randomly distributed to subjects.
} 
Room B. Numerous studies, however, find that dictators routinely make significant positive offers despite various attempts to eliminate the anomalistic behavior. Herein we explore the role of unearned money, i.e., bargainers acting over loosely held mental accounts, in this bargaining behavior.

\section{Results}

Fig. 1 provides the frequency distribution for the baseline non-earnings treatment. In this session, dictators bargained over money that was allocated by the experimenter. Contradicting game theory, $74 \%$ of these dictators offered a positive amount with $14 \%$ offering an equal split. Thirty percent of dictators offered $40 \%$ or more of their initial allocation and $50 \%$ offered $25 \%$ or more. For dictators making positive offers, the mean offer was $30.8 \%$ of the initial unearned allocation. Such divergence from game-theoretic predictions is consistent with previous findings reported in dictator games (Forsythe et al., 1994; Hoffman et al., 1996a). Interestingly, the mean allocation received by dictators making a positive offer is statistically equivalent to the overall mean of $\$ 21.43$. $^{6}$

But what role does allocating money play in these typical results? Fig. 2 illustrates the importance of this question by presenting the frequency distribution of the earnings treatment. When bargaining over earned wealth, only $24 \%$ of dictators made a positive offer with no dictators offering an equal split. And only $16 \%$ of dictators offered $15 \%$ or more of their earnings. All else equal, introducing the earnings protocol increased the rate of gametheoretical behavior from $26 \%$ to $76 \%$ of bargains. Using Fisher's exact test, the null hypothesis of equality of off-equilibrium behavior (i.e., positive offers) in dictator games with earned and unearned money is rejected ( $p$-value $<0.0001) .{ }^{7}$ Bargaining over earned money not only decreased the frequency of off-equilibrium behavior; it also diminished the magnitude of the remaining positive offers by half. For those dictators making positive offers, the mean offer was only $16.4 \%$ of earnings while being $30.8 \%$ of allocated money. A robust rank-order test confirms the distribution of offers

\footnotetext{
${ }^{6}$ An analysis did not reveal a significant relationship exists between the nominal offer amount and the dictator's budget. While the finding is subject to unobserved heterogeneity bias, this finding is related to previous work on the impact of stakes on ultimatum games (Hoffman, McCabe, \& Smith, 1996b; List \& Cherry, 2000; Slonim \& Roth, 1998).

${ }^{T}$ The raw data from the baseline and earnings experiments are provided in the Appendix.
} 


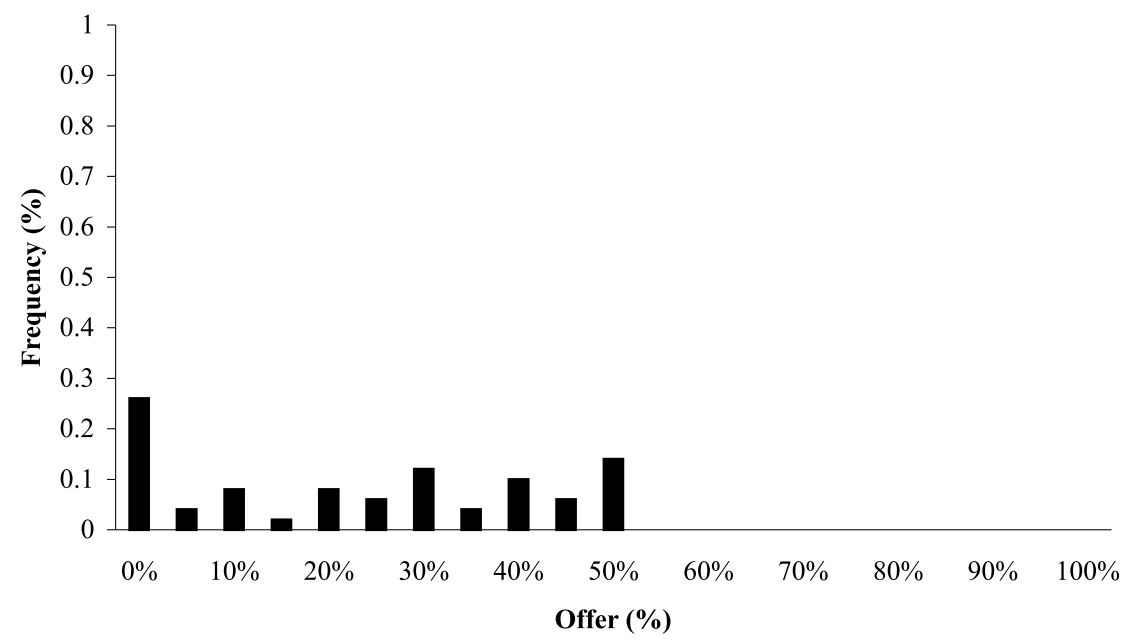

Fig. 1. Dictator game with allocated wealth $(n=50)$.

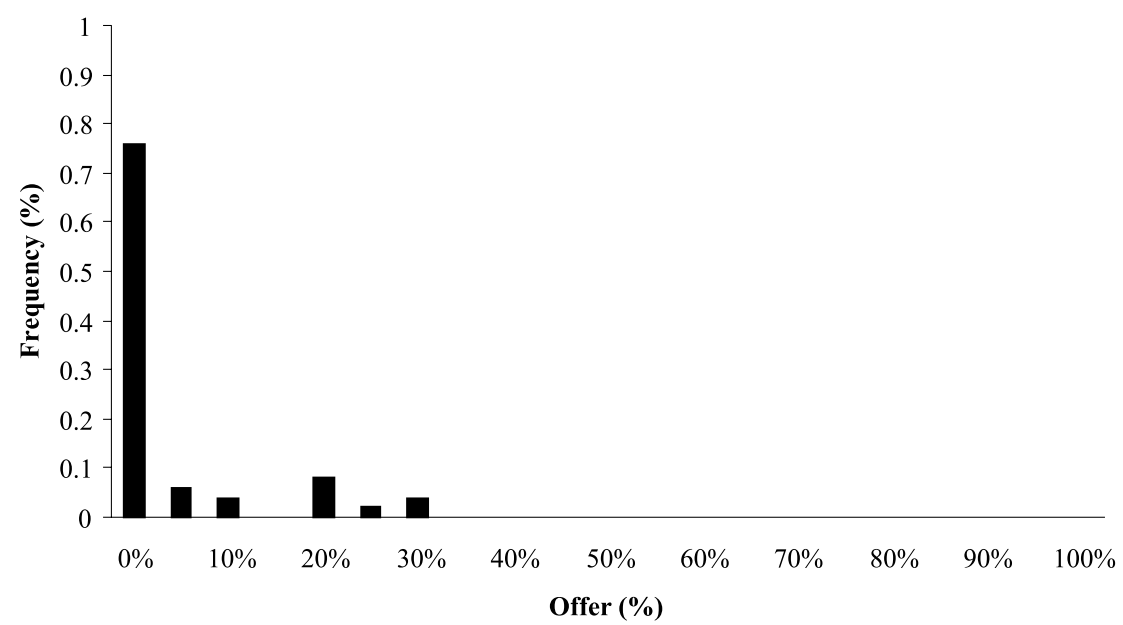

Fig. 2. Dictator game with earned wealth $(n=50)$.

is significantly different across the baseline and earnings treatments $(U=-7.70 ; p$-value $<0.0001)$.

The results provide evidence that other-regarding behavior observed in dictator games is significantly driven by the allocated nature of the money. Indeed, the earnings protocol eliminates more other-regarding behavior than any previous attempt. Specifically, the $24 \%$ rate of off-equilibrium behavior 
observed in the earnings protocol is $40 \%$ below the lowest result previously reported in the literature (Hoffman et al., 1996a).

The distinction between earned and unearned wealth in the lab is surely context dependent. The difference likely diminishes as the laboratory task becomes more demanding of time and cognitive effort. ${ }^{8}$ In any case, results from this study indicate that characteristics of the money on the table may play a role in bargaining behavior and future laboratory research may wish to consider an earnings protocol. The addition of a prior earnings session may improve the correspondence between laboratory choice and decisionmaking in the wild over earned assets while, in most cases, not infringing upon the main purpose of the laboratory study.

\section{Conclusions}

Other-regarding behavior has persisted across numerous variants of simple bargaining games. Following the notion of mental accounting, this paper examines the role of unearned money in other-regarding behavior in the dictator game. Previous evidence consistently implies substantial levels of other-regarding behavior, but the selfless actions should be put in context. The observed bargaining behavior typically involves unearned money. Results herein indicate this is an important issue. When bargainers acted over money earned in a previous session, other-regarding behavior decreased approximately $70 \%$ relative to bargainers acting over unearned money. The distinction between earned and unearned money indicates that bargaining behavior varies according to characteristics of the money on the table providing evidence of some form of mental accounting at the bargaining table. Such compartmentalization of assets has implications for future theoretical and laboratory work.

\section{Acknowledgements}

The author would like to thank the University of Wyoming and the University of Central Florida for partial funding of this research. This work

\footnotetext{
${ }^{8}$ And the persistence of the divergence between earned and unearned wealth may differ as well. For example, subjects that were allocated money and those that earned money may act more or less alike if they held the money over night. One may suspect that holding allocated money over night may significantly decrease other-regarding behavior similarly to expending effort to earn the money.
} 
benefited from Cherry's visit to the Economic Science Laboratory at the University of Arizona. Jason Shogren, David Finnoff, Peter Frykblom and two anonymous referees provided helpful comments. All errors are the sole responsibility of the author.

\section{Appendix}

Table 1

Data from dictator game with allocated money

\begin{tabular}{|c|c|c|c|}
\hline Player & Allocated money & Total $\$$ offered & Percent offered \\
\hline 1 & 16 & 0 & 0.00 \\
\hline 2 & 16 & 0 & 0.00 \\
\hline 3 & 16 & 5 & 31.25 \\
\hline 4 & 16 & 6 & 37.50 \\
\hline 5 & 16 & 8 & 50.00 \\
\hline 6 & 17 & 0 & 0.00 \\
\hline 7 & 17 & 3 & 17.65 \\
\hline 8 & 17 & 5 & 29.41 \\
\hline 9 & 17 & 7 & 41.18 \\
\hline 10 & 18 & 0 & 0.00 \\
\hline 11 & 18 & 1 & 5.56 \\
\hline 12 & 18 & 5 & 27.78 \\
\hline 13 & 18 & 8 & 44.44 \\
\hline 14 & 19 & 0 & 0.00 \\
\hline 15 & 19 & 1 & 5.26 \\
\hline 16 & 19 & 2 & 10.53 \\
\hline 17 & 20 & 0 & 0.00 \\
\hline 18 & 20 & 5 & 25. \\
\hline 19 & 20 & 7 & 35. \\
\hline 20 & 20 & 10 & 50.00 \\
\hline 21 & 20 & 10 & 50.00 \\
\hline 22 & 21 & 0 & 0.00 \\
\hline 23 & 21 & 5 & 23.81 \\
\hline 24 & 21 & 8 & 38.10 \\
\hline 25 & 21 & 10 & 47.62 \\
\hline 26 & 22 & 0 & 0.00 \\
\hline 27 & 22 & 0 & 0.00 \\
\hline 28 & 22 & 2 & 9.09 \\
\hline 29 & 22 & 5 & 22.73 \\
\hline 30 & 22 & 7 & 31.82 \\
\hline 31 & 22 & 7 & 31.82 \\
\hline 32 & 22 & 10 & 45.46 \\
\hline 33 & 22 & 11 & 50.00 \\
\hline 34 & 23 & 3 & 13.04 \\
\hline 35 & 23 & 5 & 21.74 \\
\hline
\end{tabular}


Table 1 (Continued)

\begin{tabular}{llcc}
\hline Player & Allocated money & Total \$ offered & Percent offered \\
\hline 36 & 23 & 8 & 34.78 \\
37 & 23 & 10 & 43.48 \\
38 & 24 & 0 & 0.00 \\
39 & 24 & 12 & 50.00 \\
40 & 25 & 3 & 12. \\
41 & 25 & 5 & 20.00 \\
42 & 25 & 10 & 40.00 \\
43 & 26 & 0 & 0.00 \\
44 & 26 & 0 & 0.00 \\
45 & 26 & 2 & 7.69 \\
46 & 26 & 10 & 38.46 \\
47 & 27 & 0 & 0.00 \\
48 & 28 & 5 & 17.86 \\
49 & 28 & 8 & 28.57 \\
50 & 28 & 14 & 50.00 \\
Overall average & 21.34 & 4.86 & 22.77 \\
Pos offer average & 21.43 & 6.57 & 30.77 \\
\hline
\end{tabular}

Table 2

Data from dictator game with earned money

\begin{tabular}{rllc}
\hline Player & Earned money & Total \$ offered & Percent offered \\
\hline 1 & 16 & 0 & 0.00 \\
2 & 16 & 0 & 0.00 \\
3 & 16 & 0 & 0.00 \\
4 & 16 & 0 & 0.00 \\
5 & 16 & 3 & 18.75 \\
6 & 17 & 0 & 0.00 \\
7 & 17 & 0 & 0.00 \\
8 & 17 & 1 & 5.88 \\
9 & 17 & 5 & 29.41 \\
10 & 18 & 0 & 0.00 \\
11 & 18 & 0 & 0.00 \\
12 & 18 & 0 & 0.00 \\
13 & 18 & 0 & 0.00 \\
14 & 19 & 0 & 0.00 \\
15 & 19 & 0 & 0.00 \\
16 & 19 & 4 & 21.05 \\
17 & 20 & 0 & 0.00 \\
18 & 20 & 0 & 0.00 \\
19 & 20 & 0 & 0.00 \\
20 & 20 & 0 & 0.00 \\
21 & 20 & 0 & 0.00 \\
22 & 21 & 0 & 0.00 \\
23 & 21 & & 0.00
\end{tabular}


Table 2 (Continued)

\begin{tabular}{|c|c|c|c|}
\hline Player & Earned money & Total $\$$ offered & Percent offered \\
\hline 24 & 21 & 0 & 0.00 \\
\hline 25 & 21 & 5 & 23.81 \\
\hline 26 & 22 & 0 & 0.00 \\
\hline 27 & 22 & 0 & 0.00 \\
\hline 28 & 22 & 0 & 0.00 \\
\hline 29 & 22 & 0 & 0.00 \\
\hline 30 & 22 & 0 & 0.00 \\
\hline 31 & 22 & 0 & 0.00 \\
\hline 32 & 22 & 1 & 4.55 \\
\hline 33 & 22 & 4 & 18.18 \\
\hline 34 & 23 & 0 & 0.00 \\
\hline 35 & 23 & 0 & 0.00 \\
\hline 36 & 23 & 0 & 0.00 \\
\hline 37 & 23 & 2 & 8.70 \\
\hline 38 & 24 & 0 & 0.00 \\
\hline 39 & 24 & 5 & 20.83 \\
\hline 40 & 25 & 0 & 0.00 \\
\hline 41 & 25 & 0 & 0.00 \\
\hline 42 & 25 & 2 & 8.00 \\
\hline 43 & 26 & 0 & 0.00 \\
\hline 44 & 26 & 0 & 0.00 \\
\hline 45 & 26 & 0 & 0.00 \\
\hline 46 & 26 & 8 & 30.77 \\
\hline 47 & 27 & 0 & 0.00 \\
\hline 48 & 28 & 0 & 0.00 \\
\hline 49 & 28 & 0 & 0.00 \\
\hline 50 & 28 & 2 & 7.14 \\
\hline Overall average & 21.34 & 0.84 & 3.94 \\
\hline Pos offer average & 21.67 & 3.5 & 16.42 \\
\hline
\end{tabular}

\section{References}

Arkes, H., Joyner, C., Pezzo, M., Nash, J., Siegel-Jacobs, K., \& Stone, E. (1995). The psychology of windfall gains. Organizational Behavior and Human Decision Processes, 59, 331-347.

Baik, K., Cherry, T., Kroll, S., \& Shogren, J. (1999). Endogenous timing in a gaming tournament. Theory and Decision, 41, 1-21.

Battalio, R., Kagel, J., \& Jiranyakul, K. (1990). Testing between alternative models of choice under uncertainty: Some initial results. Journal of Risk and Uncertainty, 3, 25-50.

Cherry, T., Crocker, T., \& Shogren, J. (2001). Rationality spillovers. Journal of Environmental Economics and Management, forthcoming.

Eckel, C., \& Grossman, P. (1996). Altruism in anonymous dictator games. Games and Economic Behavior, 16, 181-191.

Forsythe, R., Horowitz, J., Savin, N., \& Sefton, M. (1994). Fairness in simple bargaining experiments. Games and Economic Behavior, 6, 347-369. 
Hoffman, E., McCabe, K., Shachat, K., \& Smith, V. (1994). Preferences, property rights and anonymity in bargaining games. Games and Economic Behavior, 7, 346-380.

Hoffman, E., McCabe, K., \& Smith, V. (1996a). Social distance and other regarding behavior in dictator games. American Economic Review, 86, 653-660.

Hoffman, E., McCabe, K., \& Smith, K. (1996b). On expectations and the monetary stakes in ultimatum games. International Journal of Game Theory, 25 (3), 289-302.

Keasey, K., \& Moon, P. (1996). Gambling with the house money in capital expenditure decisions. Economics Letters, 50, 105-110.

Keeler, J., James, W., \& Abdel-Ghany, M. (1985). The relative size of windfall income and the permanent income hypothesis. Journal of Business and Economic Statistics, 3, 209-215.

List, J., \& Cherry, T. (2000). Learning to accept in ultimatum games: evidence from an experimental design that generates low offers. Experimental Economics, 3, 11-29.

Ruffle, B. (1998). More is better, but fair is fair: Tipping in the dictator and ultimatum games. Games and Economic Behavior, 23, 247-265.

Shogren, J. (1997). Self-interest and equity in a bargaining tournament with non-linear payoffs. Journal of Economic Behavior and Organization, 32, 383-394.

Slonim, R., \& Roth, E. A. (1998). Learning in high stakes ultimatum games: An experiment in the Slovak republic. Econometrica, 66, 569-596.

Thaler, R., \& Johnson, E. (1990). Gambling with the house money and trying to break even: The effects of prior outcomes on risky choice. Management Science, 36, 643-660.

Thaler, R. (1985). Mental accounting and consumer choice. Marketing Science, 4, 199-214.

Thaler, R. (1988). Anomalies: The ultimatum game. Journal of Economic Perspectives, 2, 195-206.

Thaler, R. (1990). Savings, fungibility, and mental accounts. Journal of Economic Perspectives, 4, 193-205. 